\title{
Surface-Functionalized Porous Silicon Wafers: Synthesis and Applications
}

\author{
Fahlman Bradley D. ${ }^{1}$ and Arturo Ramírez-Porras ${ }^{2}$ \\ ${ }^{1}$ Department of Chemistry, Central Michigan University, Mount Pleasant, MI, \\ ${ }^{2}$ Escuela de Física and \\ Centro de Investigación en Ciencia e Ingeniería de Materiales (CICIMA), \\ Universidad de Costa Rica, San Jose, \\ 1 United States \\ ${ }^{2}$ Costa Rica
}

\section{Introduction}

Porous silicon (PS) can be defined as a semiconductor material resulting from the electrochemical attack of a strong acid (usually hydrofluoric acid, HF), to form a network of pores with typical diameters ranging from a few micrometers to nanometers. Sometimes this material is referred to be a quantum sponge. The high surface-to-volume ratio (typically in the order of $500 \mathrm{~m}^{2} / \mathrm{cm}^{3}$ ), and their inherent electronic and transport characteristics make this material suitable for development of photonic and sensing devices.

Although the attention focus driven by PS started in 1990, some previous works have to be mentioned here. Early works on electrochemical treatment of silicon surfaces dealt with problems of anodic oxidation, electropolishing and chemical etching as early as 1937 (Güntherschulze \& Betz, 1937). A more detailed study was performed twenty years later (Schmidt \& Michel, 1957). The first mention of PS material (without being named in that way) was reported in 1956, when A. Uhlir Jr. found unusual deposits on anodized silicon samples (Uhlir, 1956). He supposed that those deposits corresponded to oxide forms of silicon. Shortly after this, Turner reported a more detailed study of anodically formed films on silicon (Turner, 1958). Years later, in 1971, Watanabe and Sakai reported for the first time that the electrochemically formed films on silicon surfaces corresponded to a porous nature (Watanabe \& Sakai, 1971). Theunissen modelled the "formation of etch channels which propagate in crystal-oriented directions in the monocrystal" of n-type silicon the following year (Theunissen, 1972). Subsequently, interest on porous silicon began to grow slowly, and important articles dealing with different aspects of the material were published.

One of the key points for which PS attracted much attention in the decade of 1990 is the capability of the material to show photoluminescence (PL). In 1984, PL was observed at a temperature of 4.2K (Pickering et al, 1984). In this work, the PL was attributed to amorphous phases present in the porous media, but no further studies could explain all features of the process. It was until 1990, when Canham's paper explained PL in terms of quantum confinement effect (Canham, 1990). This study triggered a vigorous research in the scientific community, as illustrated in Fig. 1. 


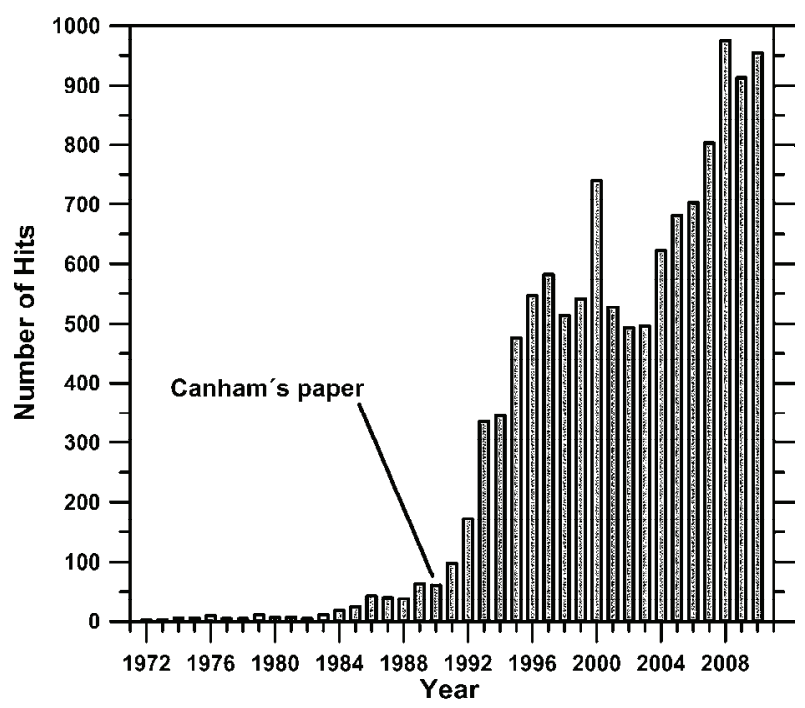

Fig. 1. Evolution of the number of publications that contain the words "porous silicon" as keywords in the period 1972 to 2010. The time location of the Canham seminal paper of 1990 is also shown.

In the early years after Canham's report, besides the quantum confinement effect, many other models have been proposed to explain the PL emission. The most important to be mentioned here are: recombination via surface states on nanostructures (Koch et al, 1993), siloxene compounds (Brandt, 1992), amorphous phases (George, 1992) and SiHX complexes (Prokes, 1992). A comprehensive model grouping the quantum confinement effect and the contribution of surface states as recombination centers was proposed by Wolkin and coworkers (Wolkin, 1999). This model was further generalized to consider stochastic variations of silicon nanocrystal sizes (Ramírez-Porras \& Weisz, 2002).

The porous silicon era really started in 1990, as can be seen in Fig. 1. Three periods of time could be extracted from this. The first one goes from 1990 to 1997, where the rate of publications in the field exhibited a rapid growth, and the dominant research topic were the PL and electroluminescence (EL) of the material in view of a possible light emitting diode (LED) development fully compatible with the standard silicon electronics industry. Certainly, one of the key moments of this period was the publication of the porous silicon advancements in the front page of the Physics Today journal of January 1997 and its accompanying article therein (Collis, 1997). A second period characterized by a decrease in the field research interest went from 1998 to 2003, with a highest peak in 2000, coinciding with the $10^{\text {th }}$ anniversary of Canham's paper. This decrease was the result of the impossibility of producing a commercially available LED made out of porous silicon. Nevertheless, some very comprehensive reviews were published in this period of time, as the one from Bisi et al (Bisi et al, 2000) and from Lehmann (Lehmann, 2002). A renaissance period started in 2004, where the research interest shifted to other applications, generally dealing with the development of sensing devices (chemical and biological sensors mainly). 
The electrochemical etch of silicon to produce porous silicon is a fairly inexpensive process, and therefore it can be implemented in a large group of countries. Fig. 2 shows the number of publications with affiliations belonging to the top 15 countries (Ramirez-Porras, 2011), taking into account the three periods of time already mentioned. It is noticeable the leader position earned by some European countries, United States and Japan in the first period, whereas in the last years China has undertaken a strong presence in the international community.

In this Chapter, we will briefly describe the synthetic procedure for porous silicon etching, followed by attempts to fabricate free-standing PS wafers. We will conclude with a discussion PS surface functionalization strategies for gas-sensing applications.

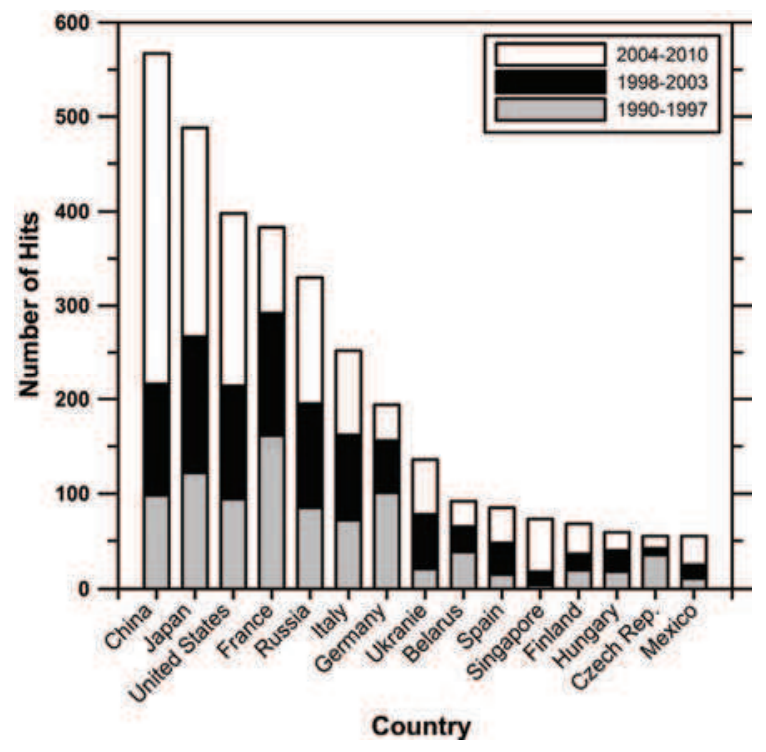

Fig. 2. Number of publications organized by affiliation that contain the words "porous silicon" as keywords. Data per country are stacked for three different periods of time: 19901997 (grey bars), 1998-2003 (black bars), and 2004-2010 (white bars).

\section{Synthesis of porous silicon}

The tunable porosity of porous silicon ( $\mathrm{p}-\mathrm{Si}$ ) and concomitant physical properties such as photoluminescence and electrical conductivity have long been exploited for solar (Menna, 1995; Vitanov, 1997), biomedical (Low, 2009; MacInnes, 2009; Alvarez, 2009), and (bio)sensing (Razi, 2008; Palestino, 2008; Janshoff, 1998) applications. The most common method used to fabricate porous silicon is electrochemical etching (anodization) of a doped Si wafer in an aqueous/ethanolic HF electrolytic solution (Fahlman, 2011). The porosity of the resultant $\mathrm{p}-\mathrm{Si}$ may be fine-tuned by altering a number of parameters such as the electrolyte concentration, etching current, anodization time, or $\mathrm{n}-/ \mathrm{p}$ - dopant concentrations (Table 1; Bisi, 2000). The diverse range of applications for $\mathrm{p}-\mathrm{Si}$ are attributed to the morphological control of p-Si fabrication, exhibiting micro- to macroporosity (Fig. 3).

A variety of anodization cells may be employed for the electrochemical etching of silicon wafers (Fig. 4). These typically employ a platinum cathode and silicon wafer anode that is in 
contact with a HF-based electrolytic solution. The use of a constant DC source is usually used to ensure a constant concentration of electrolyte at the cathode tip, resulting in a more controllable corrosion rate. Although a number of hypotheses regarding the mechanism of silicon etching have been proposed (Smith, 1992), it is generally accepted that semiconductor carriers known as holes are important for the initial oxidation steps during pore formation. Hence, for n-type $\mathrm{Si}$, an appreciable amount of anodization may only take place under light illumination, high fields, etc. The magnitude of illumination is dependent on the doping level of the native wafer. Equation 1 provides a plausible surface chemical reaction that occurs during the anodization of silicon:

$$
\mathrm{Si}+6 \mathrm{HF} \rightarrow \mathrm{H}_{2} \mathrm{SiF}_{6}+\mathrm{H}_{2}+2 \mathrm{H}^{+}+2 \mathrm{e}^{-}
$$

In order to offset the build-up of negative charge at the interface, holes must be injected from the substrate toward the $\mathrm{Si} /$ electrolyte interface during the anodization process.

\begin{tabular}{|c|c|c|c|}
\hline Experimental Parameter & $\begin{array}{c}\text { Resultant } \\
\text { Porosity }\end{array}$ & $\begin{array}{c}\text { Resultant Etching } \\
\text { Rate }\end{array}$ & $\begin{array}{c}\text { Resulting Critical } \\
\text { Current }\end{array}$ \\
\hline HF concentration & Decrease & Decrease & Increase \\
\hline Current density & Increase & Increase & No effect \\
\hline Anodization time & Increase & Minimal effect & No effect \\
\hline Temperature & No effect & No effect & Increase \\
\hline Wafer doping (p-type) & Decrease & Increase & Increase \\
\hline Wafer doping (n-type) & Increase & Increase & No effect \\
\hline
\end{tabular}

a Corresponds to an increase in each experimental parameter

Table 1. Effect of varying experimental parameters on the formation of porous silicon
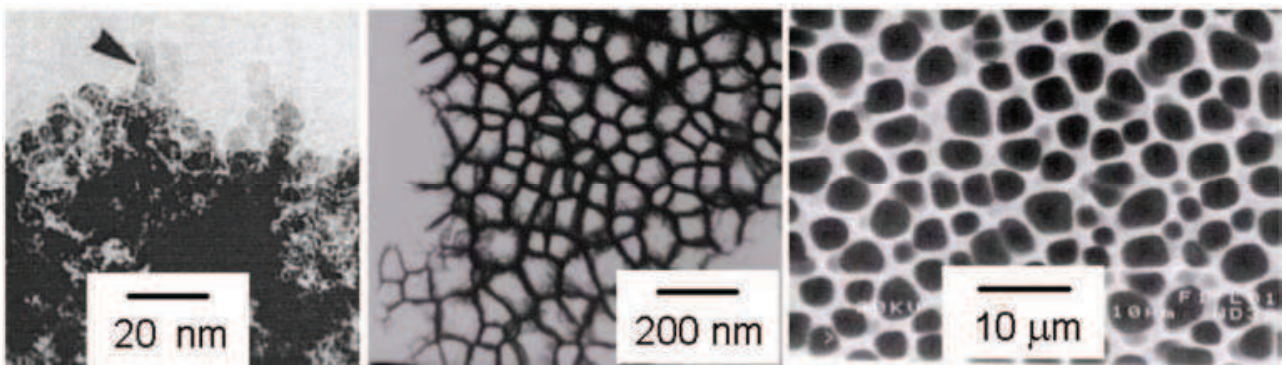

Fig. 3. TEM images of microporous (left), mesoporous (middle), and microporous (right) porous silicon. Images reproduced with permission from Gaburro, 2005.

Several techniques have been applied to characterize the interesting features that arise from the anodization process. One of these is the X-ray diffractometry (XRD), used to extract information about crystallinity. Figure 5 shows a XRD plot of both a crystalline silicon sample (c-Si) and a porous silicon sample (p-Si). The region in the vicinity of the (004) Bragg peak is shown. The X-Ray source yields two lines, the copper $K_{\alpha 1}$ and $K_{\alpha 2}$. The plots show the corresponding peaks for silicon and silicon dioxide $\left(\mathrm{SiO}_{2}\right)$. The ratio of the intensity lines between $\mathrm{SiO}_{2}$ and $\mathrm{Si}$ is an estimation of the oxide cover on the surface. This ratio is notably higher in the p-Si sample, indicating the higher level of oxidation at the porous surface. 


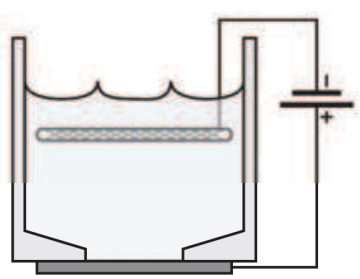

A

single tank vertical cell

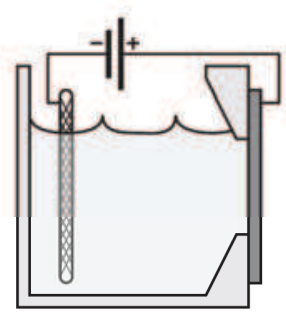

B

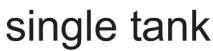
lateral cell

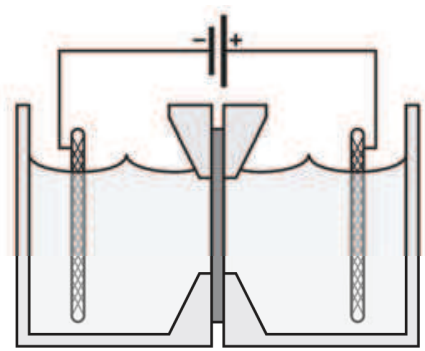

C

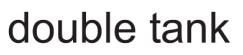
lateral cell

Fig. 4. Illustration of various types of anodization cells used to fabricate porous silicon wafers. Figure reproduced with permission from Gaburro, 2005.

The XRD peaks also contain information on the representative nanocrystal size. As seen in Figure 6, the peak can be deconvoluted into a set of peaks, one for the crystal phase and satellite peaks corresponding to nanocrystal phases. By the use of the Scherrer's equation (Guinier, 1994), that relates the full width at half maximum (FWHM) of the satellite peaks with the mean structure diameter, one is able to find the typical nanocrystal size.

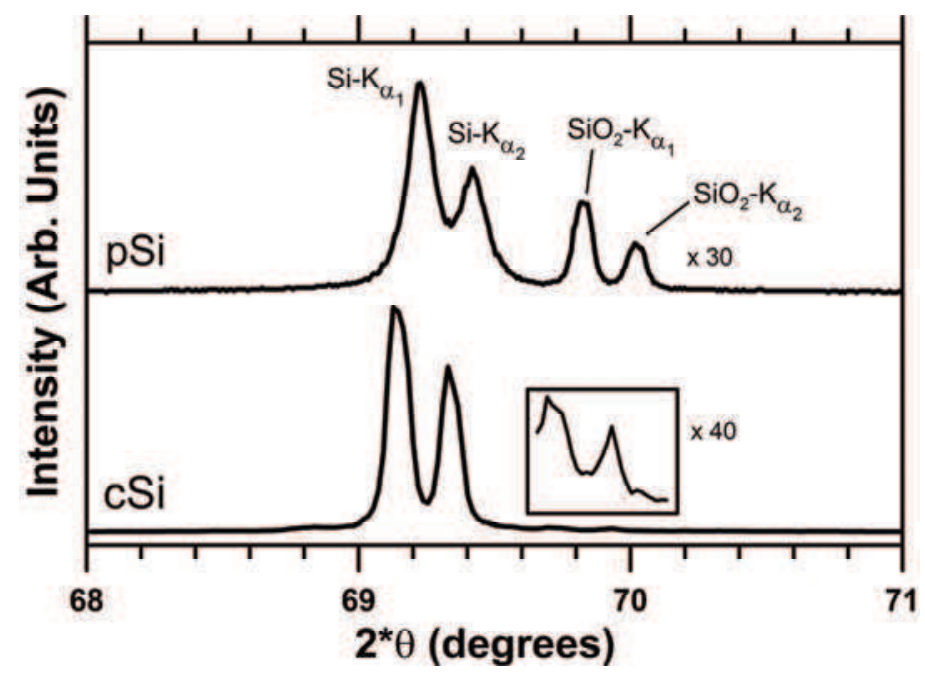

Fig. 5. XRD diffractometry plots of crystalline silicon (c-Si) and porous silicon (p-Si) surfaces near the (004) Bragg reflection zone. $K_{\alpha 1,2}$ lines for silicon and silicon dioxide are present in both cases. The intensity lines are not at the same scale (p-Si lines are increased 30 times with respect to the c-Si lines). A zoom of the silicon dioxide peaks in c-Si is also shown. (Unpublished results from the authors.) 


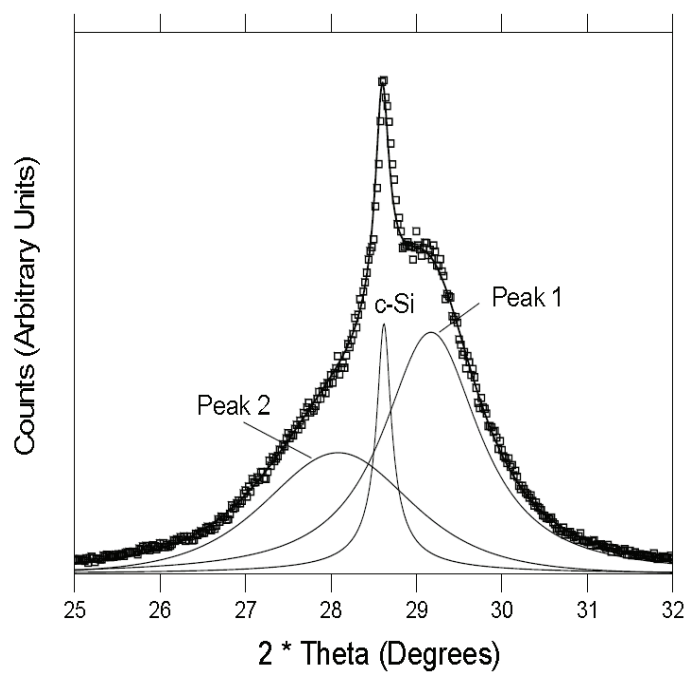

Fig. 6. XRD spectrum for a p-Si specimen near the (111) Bragg reflection plane. The satellite peaks surrounding the c-Si peak contain information on the size of the typical silicon nanocrystals, which in this case are in the $4-6 \mathrm{~nm}$ range. (Ramírez-Porras, 2002.)

\section{Fabrication of free-standing porous silicon membranes}

Whereas there are copious precedents of p-Si surfaces in contact with the native crystalline $\mathrm{Si}$ (c-Si) wafer, there are few reports of applications utilizing free-standing p-Si wafers (Liu, 2002; Bazrafkan, 2009). The most common method reported to fabricate free-standing p-Si has been electrochemical etching followed by a high-current electropolishing pulse that releases the p-Si as a free-standing flake (Papadimitriou, 2004; Lammel, 2000; Lo, 2009; Burstein, 1997). However, these methods do not yield reproducible p-Si membranes, with discrete flakes being comprised of varying thicknesses, porosities, and resultant physical/(opto)electronic properties. More recently, a sophisticated photolithographic technique has been utilized to yield free-standing p-Si microstructures (Garel, 2007). In this section, we will describe a much simpler electrochemical double-etching technique to generate free-standing $\mathrm{p}$-Si wafers in a reproducible manner.

For electrochemical etching, we employed a current of $54 \mathrm{~mA} . \mathrm{cm}^{-2}$ for $20 \mathrm{~min}$., using a ptype $\operatorname{Si}(100)$ substrate with a resistivity of $20-50 \Omega . \mathrm{cm}$. This results in a macroporosity (70\%), with average pores $2-3 \mu \mathrm{m}$ in diameter and $40-50 \mu \mathrm{m}$ depth.

In order to improve the etching uniformity over long times, the electrolyte was allowed to equilibrate in the pores during etching. This was accomplished by introducing a rest time (zero current) of $1 \mathrm{~min}$. after every $10 \mathrm{~min}$. of active etch time. In addition, an electrolyte stirrate of $240 \mathrm{rpm}$ was found to best control tghe reproducibility of our etching procedure. In order to maintain a sufficient current through the previously-etched p-Si layer and prevent subsequent leakage of the corrosive electrolyte solution, we introduced a sacrificial crystalline Si wafer prior to etching the second side (Fig. 7).

The optimum conditions for the fabrication of free-standing wafers consisted of $90 \mathrm{~min}$. of first-side etching, followed by an additional $40 \mathrm{~min}$. for the opposite side (Fig. 8). 
Interestingly, it should be noted that attempts to etch for shorter times ( $20 \mathrm{~min}$., $30 \mathrm{~min}$., 40 min.) followed by longer increments $(90-150 \mathrm{~min}$.) did not yield yield suitable free-standing wafers. Instead, a large portion of un-etched crystalline silicon remained in the interior of the sample (Fig. 9). This indicates that after a period of time, the electrical current becomes more focused on the wafer edge than across the entire wafer surface. Although porous silicon is able to transport electrical current to etch the second side, it is not able to maintain this current uniformly across wafer surface for long periods of time due to increasing sample resistivity during the etching process.

Although Searson and coworkers have reported a simple one-step etching procedure (Searson, 1991), the reported porosities were non-uniform, with the formation of copious lateral pore channels. Our attempts to etch completely through the wafer using a similar one-step process were unsuccessful (Fig. 10). For reasons stated above, this process results in etching almost completely around the circumference of the p-Si wafer, which yields a backside comprised of completely un-etched crystalline Si (Fig. 11). Further, partial etching followed by chemical removal of the remaining c-Si backside (using $1 \% \mathrm{KOH}(\mathrm{aq}$ ); Navarro, 1997) resulted in a severely damaged p-Si surface due to the rapid etching of both c-Si and p-Si by the basic solution.

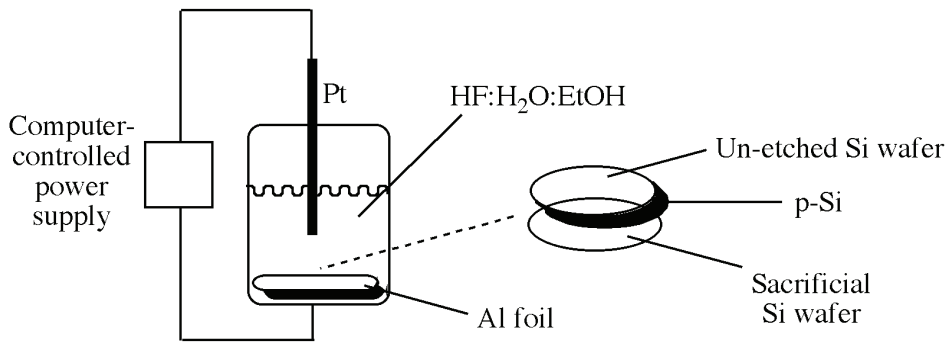

Fig. 7. Illustration of the cell used for the double electrochemical etching of silicon to yield a free-standing $\mathrm{p}$-Si wafer.

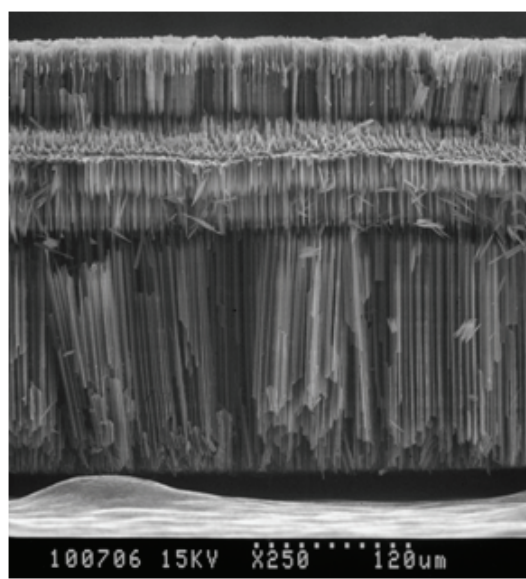

Fig. 8. Cross-section SEM image of a silicon wafer that has been electrochemically doubleetched (90 min., first-side $+40 \mathrm{~min}$. , second side). 

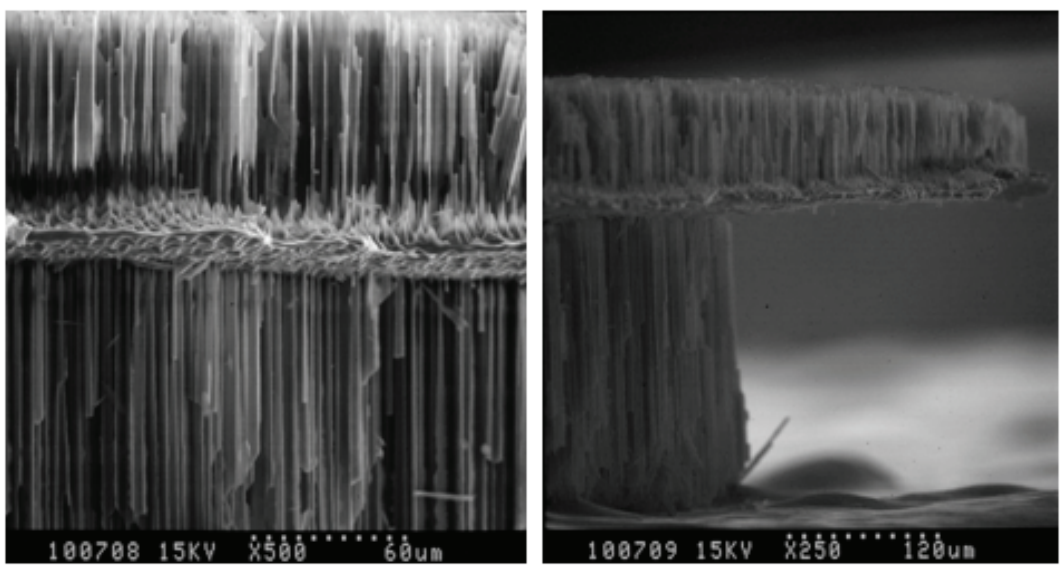

Fig. 9. Cross-section SEM images showing a region of un-etched crystalline silicon.

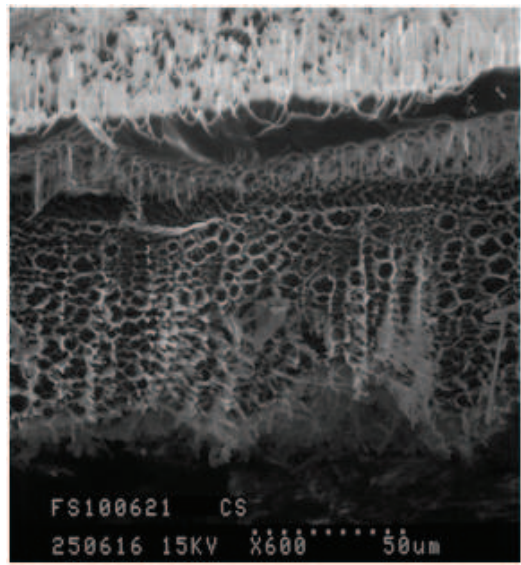

Fig. 10. Cross-section SEM image of a crystalline Si wafer following a one-step etching procedure, showing the formation of lateral pore channels.
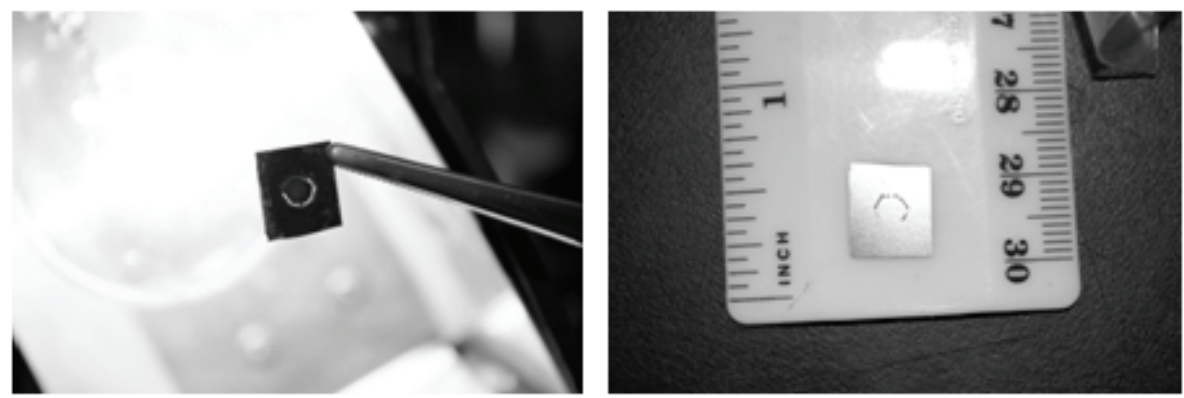

Fig. 11. Photograhs of the front (left) and backside (right) of a crystalline Si wafer, following a one-step etching procedure. 
The overall thicknesses of our free-standing wafers were of the same magnitude as the starting crystalline wafer $(c a .200 \mu \mathrm{m})$. Similar pore dimensions were formed on both sides of the wafers, virtually identical to those observed in p-Si/c-Si supported films using the same etching parameters (Stefano, 2004). Interestingly, square porous arrays are observed on only one of the sides that was in contact with aluminum foil during etching of the first side (Fig. 12). These arrays duplicate the position of creases in the aluminum foil that was used as the anode during etching.
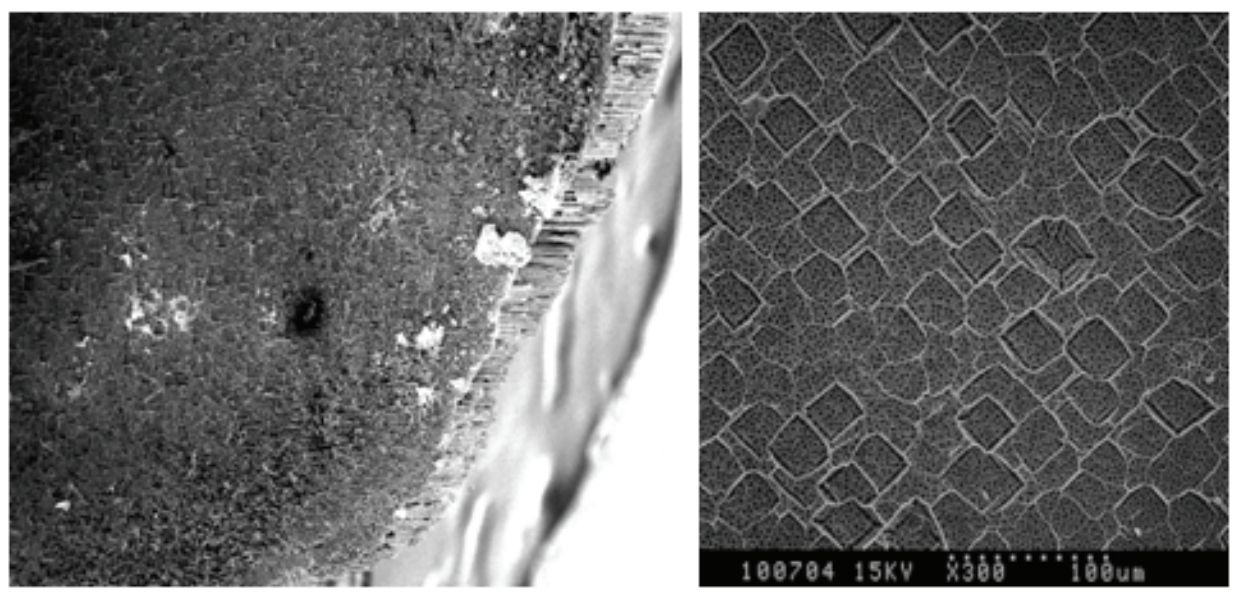

Fig. 12. SEM images illustrating the square arrays formed on the backside of the freestanding $\mathrm{p}$-Si wafer, resulting from contact with the creases of aluminum foil used as the anode during etching.

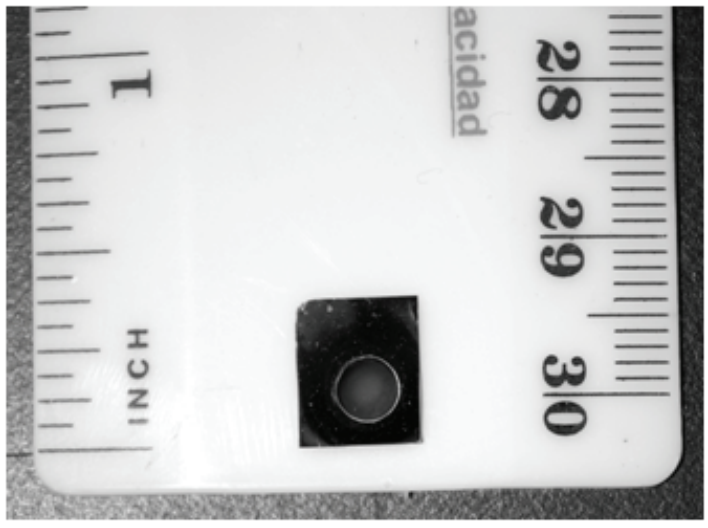

Fig. 13. Photograph illustrating uniform etching of the sacrificial crystalline Si substrate used in our double-etching procedure.

As illustrated in Figure 8, the porosity of the free-standing wafer exhibits a transitional region in its cross-section, at the point where the second-side etching is concluded. This is likely an artifact of induced diffusion currents of electrolyte at the interface of the two 
porous arrays. Nevertheless, the sacrificial crystalline Si was etched uniformly by the electrolytic solution (Fig. 13), indicating that the porous channels remain spatially homogenous throughout the entire thickness of the wafer.

\section{Applications of surface-functionalized porous silicon}

The surface of $\mathrm{p}$-Si is terminated with $\mathrm{Si}-\mathrm{H}$ groups immediately following electrochemical etching. However, these moieties are replaced by oxide groups over time due to exposure to ambient $\mathrm{O}_{2} /$ moisture. This will affect the electrical conductivity and optical properties of $\mathrm{p}$ $\mathrm{Si}$, which will alter its applicability for certain applications. Although a post-oxidation process has been used to yield a more reproducible and stable surface, it is often most desirable to introduce a surface-functionalization in order to effectively prevent postoxidation following anodization.

A surface functionalizing group may serve a two-fold benefit - preventing post-oxidation, as well as providing a chemical handle for the selective binding of gaseous/liquid adsorbant species. The latter benefit is of interest for sensor applications (Archer, 2005; Schechter, 1995), wherein one is interested in the analyte of choice being bound selectively to a surface, which will alter a specific surface physical property (e.g., conductivity, photoluminescence, etc.) that is required for analyte detection (Rossi, 2007).

Accordingly, we have assessed the utility of our free-standing p-Si wafers for gas-sensing applications. Indium contacts were soldered onto alternate sides of a p-Si wafer, and vapors of ethanol were generated by bubbling purified nitrogen gas $(800 \mathrm{sccm})$ through the liquid at $20^{\circ} \mathrm{C}$ (Fig. 14). The vapor was passed through a stainless steel chamber, which housed the porous silicon substrate in the absence of light during the analyses.

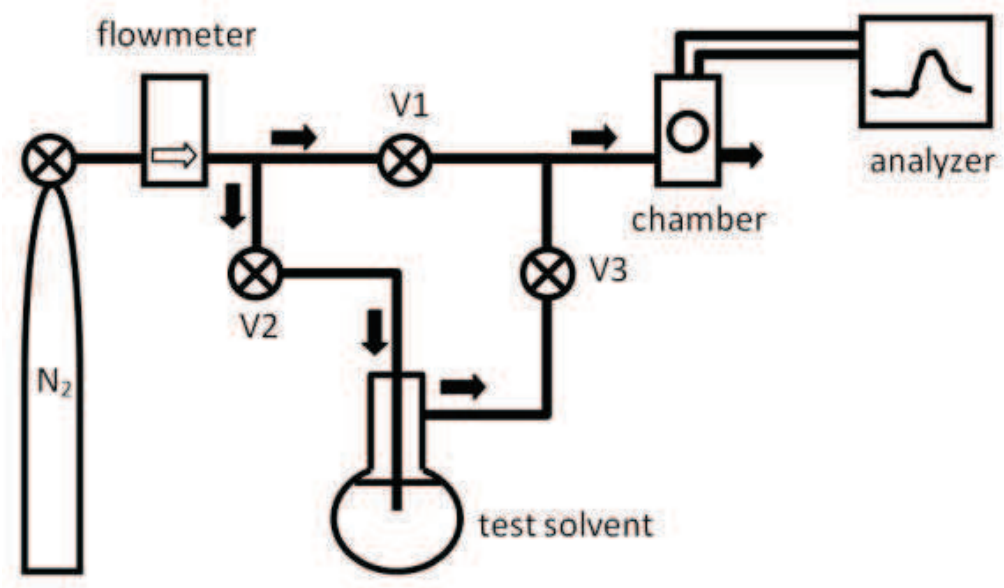

Fig. 14. Schematic of the experimental setup for vapor sensing. The concentration of the test solvent (ethanol) is controlled by varying the relative positions of valves V1 and V2/V3. The arrows indicate the direction of the gas and vapor flows.

We assessed both as-etched free standing p-Si wafers, as well as those functionalized with 4-aminopyridine. Our procedure for functionalization began by removing the native 
oxide layer by immersing the wafers for five minutes in a $2 \%$ ethanolic HF solution, followed by ethanol and THF rinses and drying under purified $\mathrm{N}_{2}$. Chlorine gas was then added to the samples, and allowed to react for 30 minutes at $95^{\circ} \mathrm{C}$. Any unreacted $\mathrm{Cl}_{2}$ was then removed from the system by purging with a flow of $\mathrm{N}_{2}$ gas for $1 \mathrm{~h}$. A $0.001 \mathrm{M}$ solution of 4-aminopyridine in THF was introduced and allowed to react for two hours at $95^{\circ} \mathrm{C}$. After rinsing the samples with THF, the wafers were stored in vials under $\mathrm{N}_{2}$ until use.

Whereas the contact angle of as-etched p-Si was $119^{\circ}$ prior to functionalization, the contact angle decreased to $35^{\circ}$ following functionalization with 4 -aminopyridine. This may be compared to contact angles of p-Si following oxidation using ozone (ca. $0^{\circ}$ ) and $\mathrm{O}_{2} /$ heat $\left(8-10^{\circ}\right)$. The IR spectrum of functionalized p-Si (Fig. 13) is also in agreement with condensed 4-aminopyridine, exhibiting characteristic $v(\mathrm{~N}-\mathrm{H}), v(\mathrm{C}-\mathrm{H})$, and $v\left(\mathrm{C}-\mathrm{C}_{\text {arom }}\right)$ resonances.

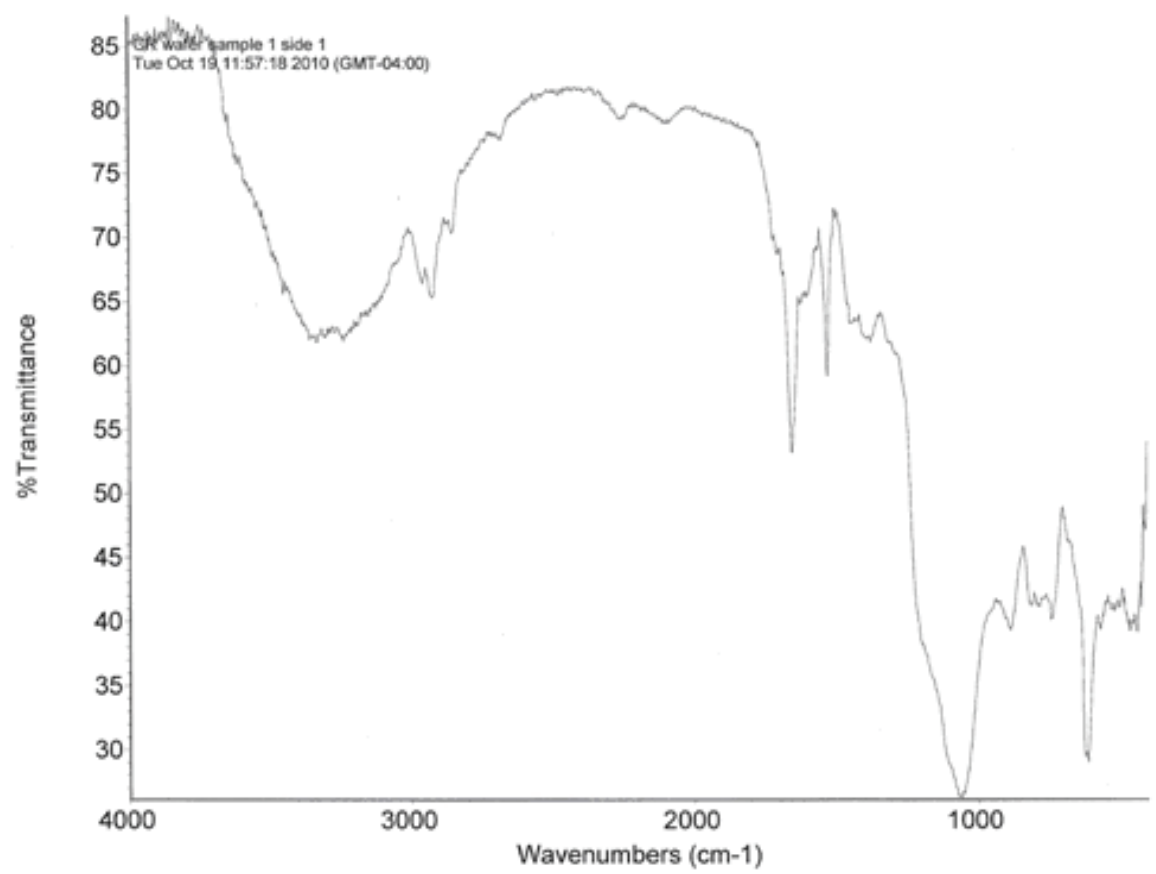

Fig. 15. DRIFT FTIR spectrum of free-standing porous silicon functionalized with 4aminopyridine.

Figure 16 illustrates the electrical conductance response of the p-Si wafer toward a $\mathrm{N}_{2}$ flux of ethanol of varying concentrations. As-etched free-standing wafers exhibit a strong conductive response. However, the recovery time is very slow due to the enhanced surface area of the substrate, concomitant with a slow release of condensed vapor from its pores (vide infra). In contrast, the amino-functionalized wafers result in a much faster response following exposure to ethanol vapor, while not significantly affecting the overall sensitivity 
of the wafer. Both as-etched and functionalized p-Si exhibited a detection limit of ca. 4 ppt toward ethanol vapor at $20^{\circ} \mathrm{C}$.

The enhanced binding reversibility of ethanol vapor onto functionalized p-Si is counterintuitive based solely on the surface polarity following functionalization. That is, for a polar organic vapor, one would expect that the highly hydrophobic H-terminated p-Si to easily release the vapor following exposure. Our observance of slow conductive baseline recovery following an ethanol flux is in agreement with Rossi et al., who report vapor sensing by $\mathrm{p}-\mathrm{Si}$ to be facilitated by condensation within the pore structure (Stefano, 2004). This mode of chemical binding would require long purging times in order to evaporatively sweep the molecules from the more pronounced pore volume of our freestanding wafers.

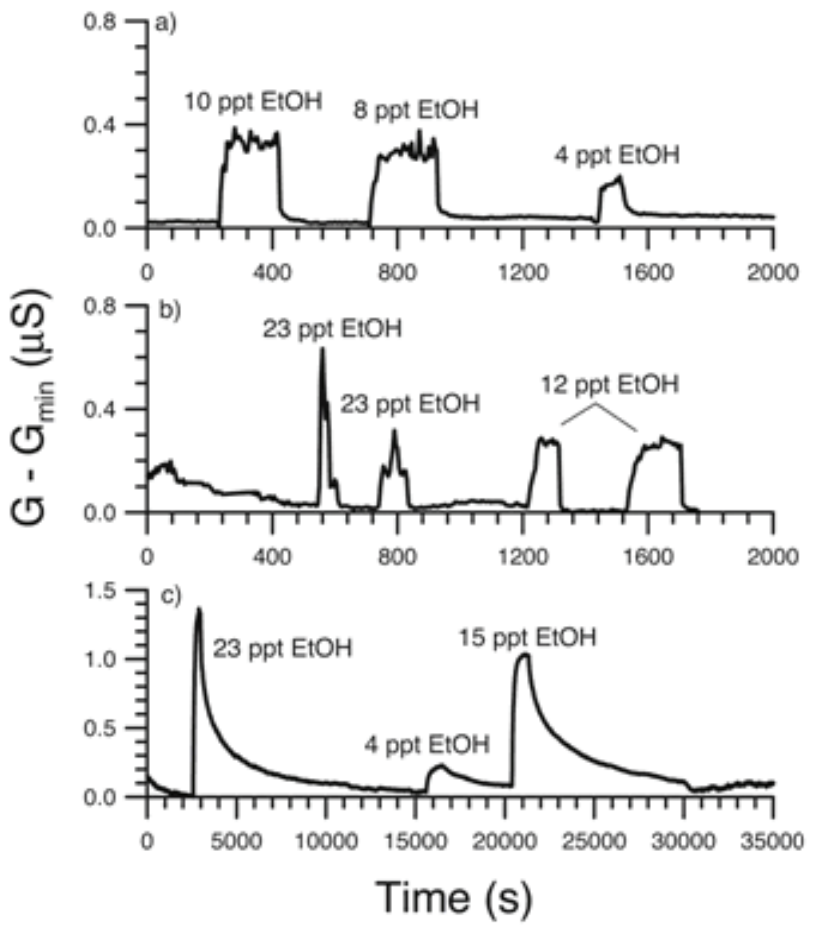

Fig. 16. Conductance response of free-standing $\mathrm{p}$-Si toward ethanol vapor at varying concentrations. Both as-etched wafers (bottom) and 4-aminopyridine-functionalized wafers (top, middle) were used.

In contrast, surfaces functionalized with 4-aminopyridine may interact with a polar vapor via intermolecular interactions, that do not require an evaporative phase change in order to release the molecules from the surface/pore structure. It should be noted that we have also observed an analogous electrical behavior for c-Si supported functionalized p-Si films; 
however, the sensitivity and concomitant detection limits were significantly inferior to the free-standing substrates reported herein.

\section{Conclusions}

In summary, we have demonstrated a simple electrochemical double-etching technique to generate free-standing p-Si wafers without lateral pore formation or residual bulk c-Si. Further, no secondary plasma or chemical treatment is required to remove the backcontact c-Si, which greatly simplifies the procedure making it widely amenable for industrial applications. As-etched and surface-functionalized wafers were shown to be effective to detect low concentrations of ethanol vapors using electrical impedance, with the latter exhibiting an extremely fast recovery time. We are working to improve the detection limits by morphological alterations to enhance the p-Si surface area, as well as expanding the sensing experiments to other organic vapors, both of which will be reported shortly.

\section{Acknowledgements}

The authors acknowledge the Vicerrectoría de Investigación of the Universidad de Costa Rica for providing funds by means of the project grant \#816-B0-063. Partial support from the Consejo Nacional para Investigaciones Científicas y Tecnológicas (CONICIT) and the Ministerio de Ciencia y Tecnología (MICIT) of Costa Rica under the Fondo de Incentivos program is also acknowledged. BDF wishes to acknowledge the Department of Chemistry and College of Science and Technology (CST) at Central Michigan University, as well as the Universidad de Costa Rica (CICIMA, CELEQ and Escuela de Física) for hosting his sabbatical.

\section{References}

Alvarez, S. D.; Derfus, A. M.; Schwartz, M. P.; Bhatia, S. N.; Sailor, M. J. (2009). Biomaterials, Vol. 30, pp. 26-34, ISSN 0142-9612.

Arai, T. \& Kragic, D. (1999). Variability of Wind and Wind Power, In: Wind Power, S.M. Muyeen, (Ed.), 289-321, Scyio, ISBN 978-953-7619-81-7, Vukovar, Croatia.

Archer, M.; Christophersen, M.; Fauchet, P. M. (2005). Sensors and Actuators B, Vol. 106, p. 347-357.

Bazrafkan, I.; Dariani, R. S. (2009). Physica B, Vol. 404, pp. 1638-1642.

Bisi, O. et al. (2000). Porous silicon: a quantum sponge structure for silicon based optoelectronics. Surface Science Reports, Vol. 38, pp. 1-136, ISSN 0167-5729.

Brandt, M.S. et al. (1992). The origin of visible luminescence from "porous silicon": A new interpretation. Solid State Communications, Vol. 81, No. 4, pp. 307-312, ISSN 00381098.

Burstein, L.; Shapira, Y.; Partee, J.; Shinar, J.; Lubianiker, Y.; Balberg, I. (1997). Phys. Rev. B, Vol. 55, p. R1930-R1933, ISSN 1098-0121. 
Canham, L.T. (1990). Silicon quantum wire array fabrication by electrochemical and chemical dissolution of wafers. Applied Physics Letters, Vol. 57, pp. 1046-1048, ISSN 0003-6951.

Collis, R.T. et al. (1997). Porous Silicon: From Luminescence to LEDs. Physics Today, Vol. 50, No. 1, pp. 24-31, ISSN 0031-9228.

Fahlman, B. D. (2011). Materials Chemistry (2nd ed.), Springer, New York, ISBN 978-94-0070692-7

Gaburro, Z.; Daldossoh, N.; Pavesi, L. (2005). Encyclopedia of Condensed Matter Physics, pp. 391-401.

Garel, O.; Breluzeau, C.; Dufour-Gergam, E.; Bosseboeuf, A.; Belier, B.; Mathet, V.; Verjus, F. (2007). J. Micromech. Microeng., Vol. 17, p. S164-S167.

George, T. et al. (1992). Microstructural investigations of light-emitting porous Si layers. Applied Physics Letters, Vol. 60, No. 19, pp. 2359-2361, ISSN 0003-6951.

Guinier, A. (1994). X-Ray Diffraction on Crystals, Imperfect Crystals, and Amorphous Bodies, Dover Publications Inc., New York.

Güntherchulze. A. \& Betz, H. (1937). Elektrolyt-Kondensatoren (Ed. Krayn, M.), Techn. Verlag H. Cram, Berlin.

Janshoff, A.; Dancil, K. -P. S.; Steinem, C.; Greiner, D. P.; Lin, V. S. -Y.; Gurtner, C.; Motesharei, K.; Sailor, M. J.; Ghadiri, M. R. J. (1998). Am. Chem. Soc., Vol. 120, pp. 12108-12116.

Koch, F. et al (1993). The luminescence of porous Si: the case for the surface state mechanism. Journal of Luminescence, Vol. 57, No. 1-6, pp. 271-281, ISSN 0013-4651.

Lammel, G.; Renaud, P. (2000). Sensors and Actuators B, Vol. 85, pp. 356-360.

Lehmann, V. (2002). Electrochemistry of Silicon: Instumentation, Science, Materials and Applications. Wiley-VCH Verlag GmbH, Federal Republic of Germany, ISBN 3-52729321-3.

Li, B.; Xu, Y. \& Choi, J. (1996). Applying Machine Learning Techniques, Proceedings of ASME 2010 4th International Conference on Energy Sustainability, pp. 14-17, ISBN 842-650823-3, Phoenix, Arizona, USA, May 17-22, 2010.

Lima, P.; Bonarini, A. \& Mataric, M. (2004). Application of Machine Learning, InTech, ISBN 978-953-7619-34-3, Vienna, Austria.

Liu, R.; Schmedake, T. A.; Li, Y. Y.; Sailor, M. J.; Fainman, Y. (2002). Sensors and Actuators B, Vol. 87, pp. 58-62.

Lo, S. -Z.; Rossi, A. M.; Murphy, T. E. (2009). Physica Status Solidi A, Vol. 206, pp. 1273-1277.

Low, S. P.; Voelcker, N. H.; Canham, L. T.; Williams, K. A. (2009). Biomaterials, Vol. 30, pp. 2873-2880, ISSN 0142-9612.

McInnes, S. J. P.; Thissen, H.; Choudhury, N. R.; Voelcker, N. H. J. (2009). Coll. Interf. Sci., Vol. 32, pp. 336-344.

Menna, P.; Francia, G. D.; La Ferrara, V. Solar Energy Mater. Solar Cells, 1995, 37, 13 - 24.

Navarro, M.; Lopez-Villegas, J. M.; Samitier, J.; Morante, J. R.; Bausells, J.; Merlos, A. (1997). J. Micromech. Microeng. Vol. 7, p. 131-132.

Palestino, G.; Legros, R.; Agarwal, V.; Perez, E.; Gergely, C. (2008). Sensors and Actuators B, Vol. 135, pp. 27-34. 
Papadimitriou, D.; Tsamis, C.; Nassiopoulou, A. G. (2004). Sensors and Actuators B, Vol. 103, pp. 356-361.

Pickering, C et al. (1984). Optical studies of the structure of porous silicon films formed in ptype degenerate and non-degenerate silicon. Journal of Physics C: Solid State Physics, Vol. 17, pp. 6535-6552, ISSN 0022-3719.

Prokes, S.M. et al. (1992). $\mathrm{SiH}_{x}$ excitation: An alternate mechanism for porous Si photoluminescence. Physical Review B, Vol. 45, No. 23, pp 13788-13791, ISSN 10980121.

Ramírez-Porras, A. (2002). Determination of nanometer-scale sizes in $\mathrm{n}^{+}$-type porous silicon by the use of X-Ray and Raman spectroscopies. Surface Review and Letters, Vol. 9, Nos. 5-6, pp. 1769-1772.

Ramírez-Porras, A. \& Weisz, S.Z. (2002). Stochastic approach to the smart quantum confinement model in porous silicon. Surface Science Letters, Vol. 515, No. 2-3, pp. L509-L513,

Ramírez-Porras, A. (2011). Search for publications in the 1972-2010 period for the keywords "porous silicon", in Scopus, 24.05.2011. Available from: http://www.scopus.com.

Razi, F.; Rahimi, F.; Irajizad A. (2008). Sensors and Actuators B, Vol. 132, pp. 40-44.

Rossi, A. M.; Wang, L.; Reipa, V.; Murphy, T. E. (2007). Biosensors and Bioelectronics, Vol. 23, pp. 741-745.

Schechter, I.; Ben-Chorin, M.; Kux, A. (1995). Anal. Chem., Vol. 67, pp. 3727-3732.

Schmidt, P.F. \& Michel, W. (1957). Anodic Formation of Oxide Films on Silicon. Journal of The Electrochemical Society, Vol. 104, No. 4, pp. 230-236, ISSN 0013-4651.

Searson, P. C. (1991). Appl. Phys. Lett., Vol. 59, p. 832-833.

Siegwart, R. (2001). Indirect Manipulation of a Sphere on a Flat Disk Using Force Information. International Journal of Advanced Robotic Systems, Vol.6, No.4, (December 2009), pp. 12-16, ISSN 1729-8806

Smith, R. L.; Collins, S. D. J. (1992). Appl. Phys., Vol. 71, p. R1.

Stefano, L. D.; Moretti, L.; Rendina, I.; Rossi, A. M. (2004.) Sensors and Actuators B, Vol. 100, p. $168-172$.

Theunissen, M.J.J. (1972). Etch Channel Formation during Anodic Dissolution of N-Type Silicon in Aqueous Hydrofluoric Acid. Journal of the Electrochemical Society, Vol. 119, No. 3, pp. 351-360, ISSN 0013-4651.

Turner, D.R. (1958). Electropolishing Silicon in Hydrofluoric Acid Solutions. Journal of The Electrochemical Society, Vol. 105, No. 7, pp. 402-408, ISSN 0013-4651.

Uhlir Jr., A. (1956). Electrolytic Shaping of Germanium and Silicon. Bell System Technical Journal, Vol. 35, No. 2, pp. 333-347, ISSN 0005-8580.

Van der Linden, S. (2010). Integrating Wind Turbine Generators (WTG's) with Energy Storage, In: Wind Power, 17.06.2010, Available from http:/ / sciyo.com/articles/show/title/wind-power-integrating-wind-turbinegenerators-wtg-s-with-energy-storage

Vitanov, P.; Kamenova, M.; Tyutyundzhiev, N.; Delibasheva, M.; Goranova, E.; Peneva, M. (1997). Thin Solid Films, Vol. 1, pp. 299-303. 
Watanabe, Y. \& Sakai, T. (1971). Application of a thick anode film to semiconductor devices. Reviews of the Electrical Communications Laboratories, Vol. 19, No. 7-8, pp. 899, ISSN: 0029-067X.

Wolkin M.V. et al. (1999). Electronic States and Luminescence in Porous Silicon Quantum Dots: The Role of Oxygen. Physical Review Letters, Vol. 82, No. 1, pp. 197-200, ISSN 0031-9007. 


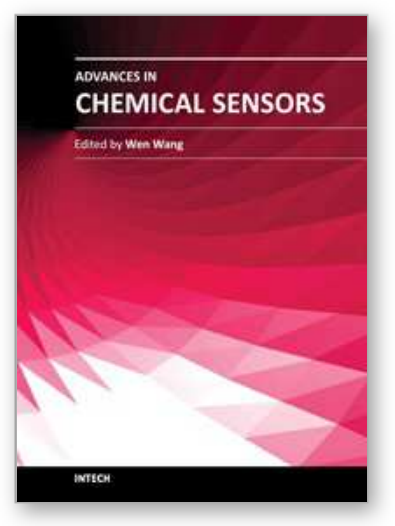

\author{
Advances in Chemical Sensors \\ Edited by Prof. Wen Wang
}

ISBN 978-953-307-792-5

Hard cover, 358 pages

Publisher InTech

Published online 20, January, 2012

Published in print edition January, 2012

The chemical sensor plays an essential role in the fields of environmental conservation and monitoring, disaster and disease prevention, and industrial analysis. A typical chemical sensor is a device that transforms chemical information in a selective and reversible way, ranging from the concentration of a specific sample component to total composition analysis, into an analytically useful signal. Much research work has been performed to achieve a chemical sensor with such excellent qualities as quick response, low cost, small size, superior sensitivity, good reversibility and selectivity, and excellent detection limit. This book introduces the latest advances on chemical sensors. It consists of 15 chapters composed by the researchers active in the field of chemical sensors, and is divided into 5 sections according to the classification following the principles of signal transducer. This collection of up-to-date information and the latest research progress on chemical sensor will provide valuable references and learning materials for all those working in the field of chemical sensors.

\title{
How to reference
}

In order to correctly reference this scholarly work, feel free to copy and paste the following:

FahIman Bradley D. and Arturo Ramírez-Porras (2012). Surface-Functionalized Porous Silicon Wafers: Synthesis and Applications, Advances in Chemical Sensors, Prof. Wen Wang (Ed.), ISBN: 978-953-307-792-5, InTech, Available from: http://www.intechopen.com/books/advances-in-chemical-sensors/surfacefunctionalized-porous-silicon-wafers-synthesis-and-applications

\section{INTECH}

open science | open minds

\section{InTech Europe}

University Campus STeP Ri

Slavka Krautzeka 83/A

51000 Rijeka, Croatia

Phone: +385 (51) 770447

Fax: +385 (51) 686166

www.intechopen.com

\section{InTech China}

Unit 405, Office Block, Hotel Equatorial Shanghai

No.65, Yan An Road (West), Shanghai, 200040, China

中国上海市延安西路65号上海国际贵都大饭店办公楼405单元

Phone: +86-21-62489820

Fax: $+86-21-62489821$ 
(C) 2012 The Author(s). Licensee IntechOpen. This is an open access article distributed under the terms of the Creative Commons Attribution 3.0 License, which permits unrestricted use, distribution, and reproduction in any medium, provided the original work is properly cited. 